\title{
Contrast sensitivity and visual disability in chronic simple glaucoma
}

\author{
J. E. ROSS, ${ }^{1}$ A. J. BRON, ${ }^{1}$ AND D. D. CLARKE ${ }^{2}$ \\ From the 'Nuffield Laboratory of Ophthalmology and the ${ }^{2}$ Department of Experimental Psychology, \\ University of Oxford, Oxford
}

SUMMARY A battery of vision tests was used to quantify visual defect in a group of 50 patients with chronic simple glaucoma. The vision tests were near and distance visual acuity, visual fields, and contrast sensitivity to static and temporally modulated sinusoidal grating patterns. Of these, static contrast sensitivity function appears to be the most sensitive method of measuring visual defect in glaucoma patients. The visual disability experienced by the glaucoma patients was quantified by means of a questionnaire, and the relationship between perceived visual disability and visual defect was examined. It was found that results from a group of tests, near visual acuity, visual field, and contrast sensitivity measures, are the best predictors of the difficulty experienced by patients in performing visually dependent daily activities.

Visual function tests are used in chronic simple glaucoma to characterise the disorder, to quantify optic nerve damage, and to estimate visual disability. Conventional psychophysical measures of visual function include the assessment of visual fields and visual acuity. These tests reveal the location and extent of the visual defect and allow the clinician to determine the severity and/or progression of the disease. However, the ability of these tests to indicate the level of disability experienced by the patient is limited.' Indeed, there have been few attempts to quantify visual disability, and although the clinical history is a most important corroboration, this is the least formal aspect of the clinical assessment.

Nevertheless, for many purposes it is assumed that judgments of visual disability can be made simply on the basis of an acuity measure. For example, an attempt to relate psychophysical tests of vision to visual disability is implicit in the United Kingdom Blindness and Partial Sight registration document ${ }^{2}$ which employs acuity as the primary criterion of disability, while the assessor is asked to take other visual factors such as visual field into consideration often without clear definition.

Some of these data were presented in a paper delivered at the International Glaucoma Symposium, Jerusalem 1983.

Correspondence to Dr J. E. Ross, Nuffield Laboratory of Ophthalmology, University of Oxford, Walton Street, Oxford OX2 6AW.
Recently contrast sensitivity function has been proposed as a valuable addition to the psychophysical tests available and has been studied in glaucoma patients..$^{3-5}$ It is said to be abnormal in ocular hypertension, ${ }^{34}$ which may indicate early optic nerve damage. In other studies, for instance of cataract, it has been suggested that contrast sensitivity is a better indicator of visual loss under everyday conditions than visual acuity. ${ }^{6}$ It might therefore be used as a test of visual disability in glaucoma and other disorders.

This study is an attempt to relate the extent of the measured visual defect to the visual disability experienced by the patient. We examined the pattern of psychophysical disturbance in 50 glaucoma patients and quantified their perceived visual disability using a fully piloted questionnaire about everyday activities.

\section{Materials and methods}

\section{SUBJECTS}

Fifty consecutive patients with bilateral chronic simple glaucoma aged between 48 and 86 were recruited from the eye clinic at Oxford Eye Hospital if they satisfied the following criteria: (1) intraocular pressure by applanation of greater than $21 \mathrm{mmHg}$ on two or more occasions, glaucomatous cupping of the optic disc greater than $0 \cdot 5$, and a glaucomatous visual field defect based upon Armaly's recommendations ${ }^{7}$; gonioscopically demonstrated open angles in any eye 
meeting all the criteria above; patients were accepted on or off treatment; (2) residence within a ten-mile radius of Oxford; (3) ability to complete the battery of psychophysical tests. This information obtained from notes and from letters to the general practitioner; (4) no history of, or present diagnosis of, eye disease other than glaucoma; (5) no medical history which might give rise to an eye disorder in the future, that is, diabetes, hypertension; (6) no optical correction greater than -6.00 dioptres and +6.00 dioptres; (7) no physical disability which might prevent normal mobility. Cataract was excluded on the basis of the presence of a lens opacity silhouetted against the red reflex on ophthalmoscopic examination. Any eye in which such an opacity was observed was excluded from the study.

Oxford Eye Hospital is the only major eye referral centre in the county of Oxfordshire, and the 50 patients recruited ( 25 males and 25 females) were a representative sample of those eligible on the basis of the above criteria. There were 93 subjects in the control group ( 42 males and 51 females) who provided normative data stratified by age. All control subjects had normal eyes on ophthalmological examination. The control group matched the patient group for age, sex, and socioeconomic status and had distance Snellen acuity of $6 / 9$ or better in each eye separately.

\section{APPARATUS}

Distance visual acuity was measured on the Snellen test chart at $6 \mathrm{~m}$ using a forced choice procedure. ${ }^{8}$ Near visual acuity was measured on the Bailey Lovie near vision chart.

Visual fields were measured on the Topcon $\mathrm{SBP} / 11 \mathrm{H}$ projection perimeter using the $\mathrm{I} 2 \mathrm{e}, \mathrm{I} 4 \mathrm{e}$, and $\mathrm{V} 4 \mathrm{e}$ targets. Background illumination was maintained at 31.5 apostilbs for each test target.

Contrast sensitivity: static gratings $(C S F(S))$. Stationary vertical sinewave gratings of variable spatial frequency were generated on a display oscilloscope by a two-channel computer addressed microprocessor wave form generator. ${ }^{9}$ Contrast of the grating pattern was adjusted by a computer linked attenuator. Contrast is defined as $\left(\mathrm{L}_{\max }-\mathrm{L}_{\text {min }} / \mathrm{L}_{\text {max }}+\right.$ $L_{\min }$ ) where $L_{\max }$ and $L_{\min }$ are the maximum and minimum luminances respectively of the grating bars.

The stimulus area on the oscilloscope screen was rectangular, $30 \mathrm{~cm}$ by $20 \mathrm{~cm}$, with a matt grey surround. Mean screen luminance was $\mathbf{3 0 0}$ candelas per metre squared $\left(\mathrm{cd} / \mathrm{m}^{2}\right)$ and was independent of the contrast of the spatial frequency being displayed. Contrast values were linear for the six spatial frequencies which were used $(0.40,0.95,2.88,6.73$, $12 \cdot 70,19 \cdot 25$ cycles per degree of visual angle (cpd)).

A preliminary routine was employed to familiarise the subject with the test. The six gratings were demonstrated to the subject, and an approximate contrast threshold for each spatial frequency was established. Subsequently two preprogrammed sequences were used: a double staircase technique ${ }^{10}$ followed by a series of reversals. " The threshold was computed from the mean of three reversals. In the preprogrammed sequences the choice as to which spatial frequencies were presented was made randomly by the computer.

The subject viewed the screen from a distance of $280 \mathrm{~cm}$ and rested his chin on an adjustable chin rest. At this distance the screen subtended a visual angle of $6^{\circ}$ at the nodal point of the observer's eye. The test was described, and the subject was asked to respond to the presence of a vertical grating pattern, however faint, by pressing a hand-held buzzer.

Contrast sensitivity: temporally modulated gratings $(C S F(T))$. Sinewave gratings of variable spatial and temporal frequency were generated on a display oscilloscope using a microprocessor controlled device. Front panel switches on the microprocessor permitted manual control of spatial and temporal frequency and sine or square modulation. The size and mean luminance of the screen were the same as for the CSF(S) test.

The contrast of the grating was changed by adjusting the modulation voltage in decibels using a logarithmic potentiometer. Further adjustment of the contrast could be made using an MF Attenuator TF2162 which has a range of $111 \mathrm{db}$. The modulation voltage was set to operate in the range of $0 \cdot 1$ to $40 \mathrm{db}$ and a contrast voltage reading was displayed on a Farnell digital multimeter.

The method of limits was employed to obtain visual threshold measurements. Four stimulus conditions were employed: $6.50 \mathrm{cpd}$ and $0.8 \mathrm{~Hz} ; 6.50 \mathrm{cpd}$ and 10 $\mathrm{Hz} ; 0.45 \mathrm{cpd}$ and $0.8 \mathrm{~Hz} ; 0.45 \mathrm{cpd}$ and $10 \mathrm{~Hz}$. Temporal modulation was achieved by shifting the phase of the sinusoidal grating sinusoidally by $180^{\circ}$.

The subject viewed the screen from a distance of $180 \mathrm{~cm}$. After a preliminary demonstration of each stimulus the subject was asked to press the hand-held buzzer when one of the four stimuli appeared, however faint. Trials were not included in the final computation of the threshold until the response reached an asymptotic level, and there were minimal variations between responses. After the asymptotic level had been reached the mean of the next four recorded values was used to compute the contrast sensitivity threshold.

\section{QUESTIONNAIRE}

Perceived visual disability was quantified using a fully piloted questionnaire of 84 questions about the effect of vision on everyday activities. The questionnaire covered five life areas: self care, domestic tasks, 
navigation, travel, and leisure. Responses were recorded on a five-point unipolar rating scale from 'no disability' to 'severe disability'. The questionnaire was presented to individual subjects by J.E.R. in an interview lasting approximately one hour.

Examination procedures for both vision tests and the questionnaire schedule were standardised, and all measurements were found to be reliable. Reliability was measured on a test-retest basis for each variable, and high positive correlation coefficients between test sessions were obtained $(r>0 \cdot 80)$.

\section{Results}

\section{VISUAL FUNCTION TESTS}

Control subjects. Unlike the patients not every control subject completed all the vision tests and the questionnaire. Table 1 shows the number of tests completed by male and female control subjects. The mean age of the male control group was 69.35 years (SD 8.63) and of the female control group 70.40 years (SD 8.67).
Table 1 Number of control subjects who completed each test

\begin{tabular}{llll}
\hline & Male & Female & Total \\
\hline Snellen acuity & 42 & 51 & 93 \\
Bailey Lovie near acuity & 27 & 31 & 58 \\
Perimetry & 32 & 33 & 65 \\
CSF (S) & 22 & 31 & 53 \\
CSF (T) & 23 & 33 & 56 \\
Questionnaire & 10 & 10 & 20 \\
\hline
\end{tabular}

Results of the psychophysical tests were stratified by age and sex. There were no significant differences between the performance of male and female subjects on any of the tests, but there was an age related fall in visual acuity, visual field isoptre size, $\operatorname{CSF}(\mathrm{S})$, and $\mathrm{CSF}(\mathrm{T})$. For this reason all comparisons of psychophysical test results were age matched.

Chronic simple glaucoma patients. There were 50 glaucoma patients in the study group, 25 males (mean age 70.05 years, SD 9.68) and 25 females (mean age 70.77 years, SD 9.08). One-way analyses of variance

Table 2 Visual function tests: one-way analysis of variance between patients and controls for monocular and binocular viewing

\begin{tabular}{|c|c|c|c|c|c|c|}
\hline \multicolumn{7}{|c|}{ Monocular viewing } \\
\hline \multirow[t]{2}{*}{ Test stimulus } & \multirow{2}{*}{$\begin{array}{l}\text { Units of } \\
\text { measurement }\end{array}$} & \multirow[t]{2}{*}{ Fvalue } & \multicolumn{2}{|c|}{ Group mean value } & \multirow{2}{*}{$\begin{array}{l}\text { Tail } \\
\text { probability }\end{array}$} & \multirow{2}{*}{$\begin{array}{l}\text { Degrees of } \\
\text { freedom }\end{array}$} \\
\hline & & & Glaucoma & Control & & \\
\hline $\begin{array}{l}\text { Snellen distance } \\
\text { acuity }\end{array}$ & $\begin{array}{l}\text { Log minimum angle } \\
\text { of resolution }\end{array}$ & $15 \cdot 5$ & $0 \cdot 226$ & 0.0896 & $0 \cdot 002$ & 1184 \\
\hline $\operatorname{CSF}(S) 1$ & Contrast sensitivity & $11 \cdot 26$ & $1 \cdot 026$ & 1.435 & 0.001 & 1204 \\
\hline $\mathrm{CSF}$ (S) 2 & " & $18 \cdot 31$ & $1 \cdot 507$ & $2 \cdot 051$ & $<0.0001$ & \\
\hline CSF (S) 3 & $"$ & 51.41 & 1.626 & $2 \cdot 542$ & $<0 \cdot 0001$ & \\
\hline CSF (S) 4 & $"$ & $54 \cdot 21$ & $1 \cdot 303$ & $2 \cdot 284$ & $<0 \cdot 0001$ & \\
\hline CSF (S) 5 & $"$ & $19 \cdot 74$ & 0.796 & $1 \cdot 736$ & $<0.0001$ & \\
\hline CSF (S) 6 & $"$ & $21 \cdot 50$ & 0.415 & $1 \cdot 252$ & $<0 \cdot 0001$ & \\
\hline $\operatorname{CSF}(\mathrm{T}) 1$ & $"$ & $20 \cdot 34$ & 0.628 & $1 \cdot 300$ & $<0 \cdot 0001$ & 1210 \\
\hline $\operatorname{CSF}(\mathrm{T}) 2$ & $"$ & $51 \cdot 52$ & $0 \cdot 335$ & 0.997 & $<0 \cdot 0001$ & \\
\hline $\operatorname{CSF}(\mathrm{T}) 3$ & $"$ & $18 \cdot 50$ & 0.402 & $0 \cdot 886$ & $<0 \cdot 0001$ & \\
\hline $\operatorname{CSF}(T) 4$ & $"$ & $16 \cdot 35$ & $0 \cdot 816$ & $1 \cdot 334$ & 0.0003 & \\
\hline \multicolumn{7}{|l|}{ Binocular viewing } \\
\hline $\begin{array}{l}\text { Snellen distance } \\
\text { acuity }\end{array}$ & $\begin{array}{l}\text { Log minimum angle } \\
\text { of resolution }\end{array}$ & $2 \cdot 82$ & $0 \cdot 158$ & 0.0577 & 0.0952 & 1141 \\
\hline $\begin{array}{l}\text { Bailey Lovie } \\
\text { near acuity }\end{array}$ & " & $17 \cdot 50$ & $0 \cdot 511$ & $0 \cdot 288$ & $0 \cdot 0012$ & 1106 \\
\hline Bioc $I_{2} e$ & Pixels & $67 \cdot 76$ & $4 \cdot 558$ & $18 \cdot 50$ & $<0.0001$ & 1113 \\
\hline $\mathrm{Bioc} \mathrm{I}_{4} \mathrm{e}$ & $"$ & $92 \cdot 73$ & $44 \cdot 384$ & 99.99 & $<0 \cdot 0001$ & \\
\hline Bioc $V_{4} e$ & $"$ & $52 \cdot 70$ & $103 \cdot 506$ & $171 \cdot 40$ & $<0.0001$ & \\
\hline $\operatorname{CSF}(S) 1$ & Contrast sensitivity & $5 \cdot 39$ & $1 \cdot 337$ & 1.494 & 0.035 & 1101 \\
\hline CSF (S) 2 & t & $16 \cdot 54$ & $1 \cdot 843$ & $2 \cdot 098$ & $0 \cdot 0003$ & \\
\hline CSF (S) 3 & $"$ & $56 \cdot 91$ & 1.989 & $2 \cdot 630$ & $<0.0001$ & \\
\hline CSF (S) 4 & $"$ & 51.93 & 1.624 & $2 \cdot 382$ & $<0 \cdot 0001$ & \\
\hline CSF (S) 5 & $"$ & 43.08 & $1 \cdot 038$ & 1.836 & $<0.0001$ & \\
\hline CSF (S) 6 & $"$ & $44 \cdot 23$ & 0.507 & $1 \cdot 350$ & $<0 \cdot 0001$ & \\
\hline CSF (T) & $"$ & $18 \cdot 34$ & $0 \cdot 812$ & $1 \cdot 394$ & $<0.0001$ & 1104 \\
\hline CSF (T) & $"$ & $38 \cdot 16$ & 0.482 & 1.086 & $<0 \cdot 0001$ & \\
\hline $\operatorname{CSF}(\mathrm{T})$ & $"$ & $9 \cdot 22$ & 0.692 & 1.009 & 0.0031 & \\
\hline $\operatorname{CSF}(\mathrm{T})$ & $"$ & $4 \cdot 83$ & $1 \cdot 224$ & 1.449 & 0.0303 & \\
\hline
\end{tabular}




\section{TYPE 1}
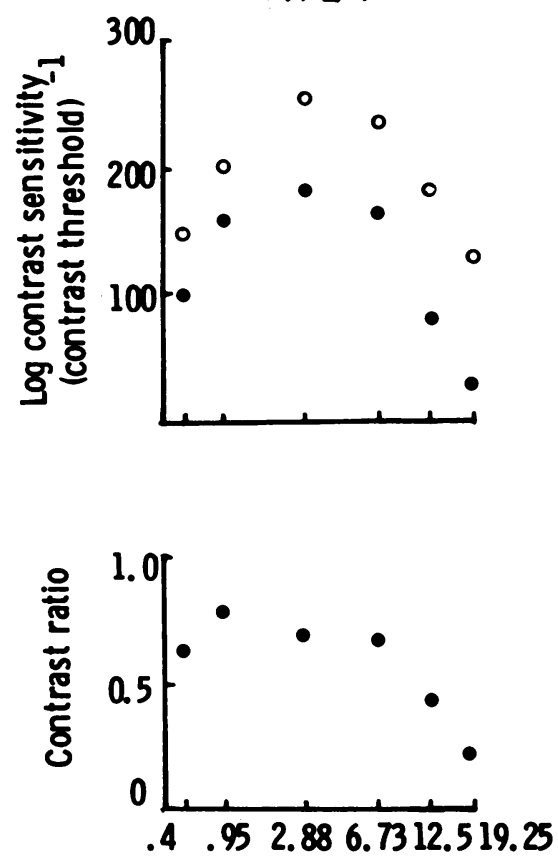

TYPE 2
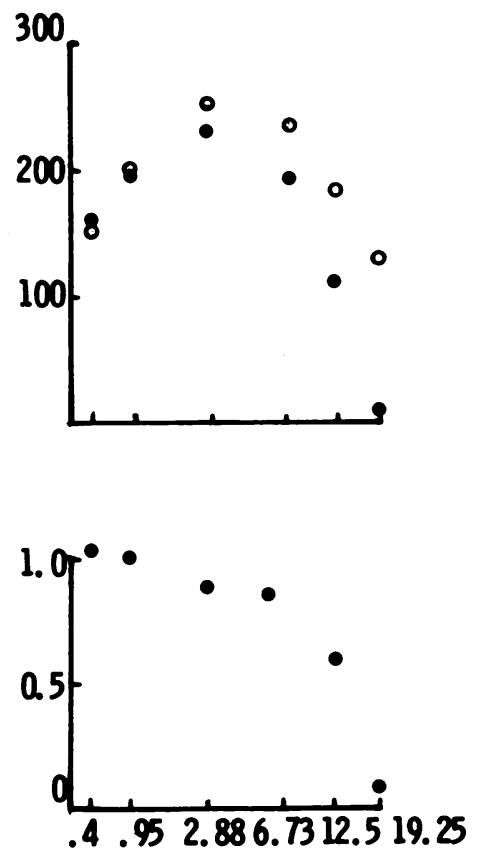

TYPE 3
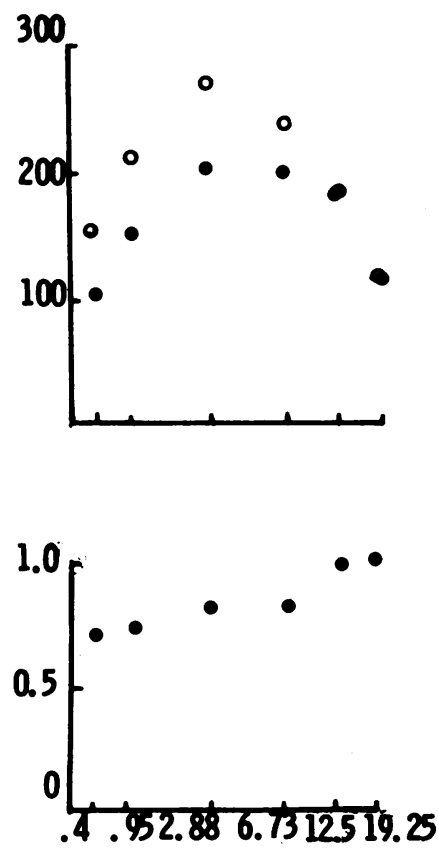

\section{Spatial frequency ( cycles / degree)}

Fig. 1 Three types of contrast sensitivity response for glaucoma patients are demonstrated. In the upper graphs examples of contrast sensitivity plotted against spatial frequency are shown for glaucoma patients as (O) and aged matched controls as (O). In the lower graphs are plotted the 'sensitivity loss' through disease. These values are derived from the ratio of the patient's response to the control response. A contrast ratio of 1.00 is taken to be the normal response, and departures from this value represent loss of sensitivity.

were performed to test for any significant differences between the responses of the chronic simple glaucoma and control groups to the visual function tests (Table 2). There were significant differences between the two groups for monocular distance acuity, near visual acuity, visual field isoptre size, $\operatorname{CSF}(\mathrm{S})$, and CSF(T). More than half of the patients had binocular distance visual acuity of $6 / 6$, and the lowest Snellen acuity score was $6 / 24$. Mean acuity was $6 / 7 \cdot 5$. A somewhat lower acuity was achieved with monocular viewing, range $6 / 6$ to no perception of light, mean value $6 / 9$. The mean value for near visual acuity was N6. As expected from the inclusion criteria the visual field plots revealed typical glaucomatous loss which varied in severity from mild field loss, that is, central depression and nasal step, to severe loss, that is, absent central fields (I2e), and gross constriction or absence of fields to larger brighter targets.

The $\operatorname{CSF}(\mathrm{S})$ results for monocular and binocular viewing fell roughly into two discrete response categories. A type 1 response was characterised by a depression of contrast sensitivity for all spatial fre- quencies and a type 2 response by an attenuation at the high spatial frequency end of the curve only. In addition, a small number of patients fell into a third category (type 3 ) with attenuation at the low spatial frequency end of the curve and a normal high spatial frequency response (Fig. 1). In the lower portion of the figure the response of an age matched normal eye is compared with that of a diseased eye. The ratio of these responses represents sensitivity loss due to disease.

Patients with a type 1 response in one eye and a type 2 in the other usually gave a binocular type 2 response. For approximately half of the patients the visual loss was evident throughout the contrast sensitivity curve, and of the remaining 26 patients 16 had reduced sensitivity to high spatial frequencies only, four had reduced sensitivity to low spatial frequencies only, and six demonstrated no specific losses.

With the exception of two patients all the patients demonstrated reduced sensitivity to one or more test stimuli to the flickering gratings $(\mathrm{CSF}(\mathrm{T}) .62 \%$ of patients gave responses which were greater than or 
equal to two standard deviations away from age matched norms to the low spatial frequency temporally modulated test stimulus $(10 \mathrm{~Hz})$.

In order to determine which of the newer psychophysical test stimuli (CSF(S) and CSF(T)) was most sensitive in evaluating visual dysfunction we calculated the sensitivity and specificity for each stimulus. The calculations were evaluated with the assumption that a monocular response which was greater than 2 $\mathrm{SD}$ from the mean of the age matched control group is abnormal. The most sensitive stimulus was a static presentation at $2.88 \mathrm{cpd}$. Ninetyfour percent of the glaucoma patients had abnormal responses at this point on the contrast sensitivity curve.

The relationship between visual field and $\operatorname{CSF}(\mathrm{S})$ was examined. There were 37 eyes with mild field loss (a field of $15^{\circ}$ or more around fixation for the I2e isoptre). Thirty of these eyes had abnormal CSF(S) (that is, responses greater than or equal to $2 \mathrm{SD}$ away from age matched norms) but no acuity defect. All eyes with greater field loss than the above had abnormal $\operatorname{CSF}(S)$, and in some of these patients the $\mathrm{CSF}(\mathrm{S})$ values were reduced tenfold when compared with the values obtained from age matched normal subjects.

\section{QUESTIONNAIRE}

Twenty of the control subjects completed the questionnaire, and in every case the subject accrued the maximum score (no disability) for every question.

Disability data from the questionnaire were analysed by factor analysis. ${ }^{12}$ Firstly, all 84 questions were included in this analysis in which four factors were identified. These results were used to eliminate some of the items in the questionnaire. Thus questions with loadings of $<0.60$ on a given factor were not included in subsequent analyses. Paraphrased versions of the questions in the reduced questionnaire are presented in Table 3. Secondly, factor analysis

Table 3 Paraphrased versions of questions used in statistical analysis

Difficulty with dressing

Seeing food on plate

Time taken to eat food

Difficulty cooking

Difficulty with housework

Confidence in street

Care crossing street

Seeing moving vehicles

Care on uneven pavement

Difficulty on outside steps

Moving in unfamiliar places

Difficulty in walking in dark

Reading instructions on packets etc.

Enjoyment of television

Recognising faces

Effect of eyesight on leisure activities was performed on the remaining questionnaire responses. Four factors emerged each containing a unique combination of questionnaire responses. These factors related to navigation out of doors, near vision, navigation at night, and vision when cooking. In particular it was found that questions relating to the care that is necessary when negotiating streets and pavements had high loadings on the first factor 'Navigation'.

Canonical correlation analysis was performed in order to assess the degree of relationship between the vision test and the questionnaire responses. Disability values for use in the canonical correlation analysis were derived from the factor analysis. An overall questionnaire score (a factor score) was produced for each patient during the factor analysis on a scale with both negative (great disability) and positive (little disability) axes. Since visual disability relates to binocular vision only binocular vision test results were used. In the case of visual fields the right and left eye fields were superimposed to produce a biocular field score.

As a result of the analyses (Table 4) a number of

Table 4 Results of canonical correlation analysis for glaucoma patients. Factor scores and vision tests results were used for input data. Decimal point omitted

\begin{tabular}{|c|c|c|c|c|}
\hline Variable & $C N V R F I$ & $C N V R F 2$ & $C N V R F 3$ & CNVRF4 \\
\hline Factor 1 & 977 & 043 & 150 & -147 \\
\hline Factor 2 & 300 & 059 & 938 & 163 \\
\hline Factor 3 & 652 & 543 & -213 & 485 \\
\hline Factor 4 & 413 & 712 & 130 & -554 \\
\hline Variable & CNVRSI & CNVRS2 & CNVRS3 & CNVRS4 \\
\hline SNac & 245 & 735 & 254 & -050 \\
\hline $\mathrm{Nac}$ & 801 & 022 & 271 & -100 \\
\hline $\mathrm{CSF}(\mathrm{S}) 1$ & 485 & 077 & 379 & 210 \\
\hline CSF(S)2 & 545 & -091 & 431 & 278 \\
\hline CSF(S)3 & 530 & -154 & 525 & 061 \\
\hline CSF(S)4 & 506 & -102 & 551 & -007 \\
\hline CSF(S)5 & 333 & -030 & 769 & -077 \\
\hline CSF(S)6 & 484 & -095 & 489 & -080 \\
\hline $\mathrm{CSF}(\mathrm{T}) 1$ & 406 & 163 & 249 & -167 \\
\hline $\operatorname{CSF}(\mathrm{T}) 2$ & 466 & 166 & 213 & -039 \\
\hline $\mathrm{CSF}(\mathrm{T}) 3$ & 376 & 377 & 072 & 162 \\
\hline $\operatorname{CSF}(T) 4$ & 554 & 211 & 099 & 145 \\
\hline $\mathrm{BIOC}_{2} \mathrm{e}$ & 455 & -050 & 187 & -200 \\
\hline $\mathrm{BIOC} \mathrm{I}_{4} \mathrm{e}$ & 752 & 062 & 063 & -316 \\
\hline $\mathrm{BIOC} \mathrm{V}_{4} \mathrm{e}$ & 765 & 184 & 119 & -080 \\
\hline Eigenvalue & $0 \cdot 70833$ & 0.36561 & 0.23833 & $0 \cdot 16049$ \\
\hline Correlation & $0 \cdot 84162$ & 0.60441 & 0.48819 & 0.40061 \\
\hline$\chi^{2}$ & $82 \cdot 16$ & $34 \cdot 72$ & $17 \cdot 22$ & $6 \cdot 73$ \\
\hline df & 64 & 45 & 28 & 13 \\
\hline $\begin{array}{l}\text { Tail } \\
\text { probability }\end{array}$ & 0.06 & $0 \cdot 866$ & 0.944 & 0.915 \\
\hline
\end{tabular}

The first $\chi^{2}$ value refers to an overall significance value for the computations rather than one which is computed for the first canonical variable pair alone. However, the first pair of variates will account for the major part of that significance. 


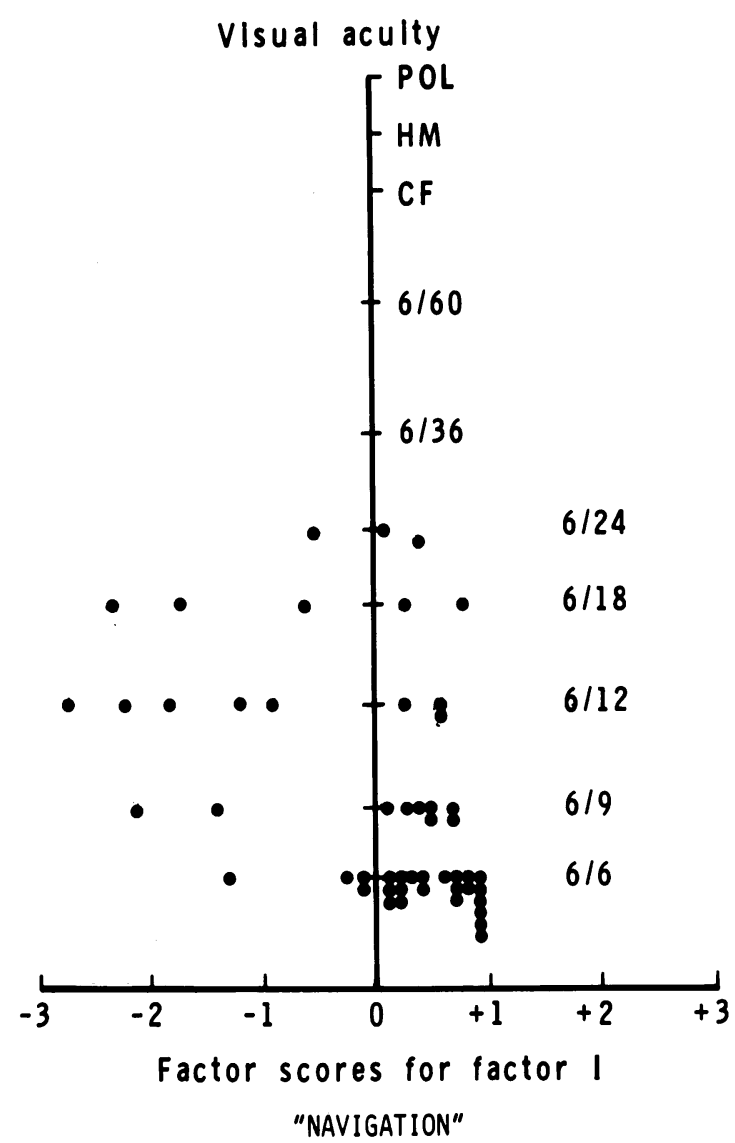

Fig. 2 The relationship between binocular Snellen acuity scores and perceived disability are shown. Snellen acuity is plotted on the vertical axis and perceived disability measured as a factor score is plotted on the horizontal axis. The factor scores are derived from a factor analysis. A negative factor score indicates greater disability than a positive score. Each point on the graph represents an individual visual acuity value plotted as a measure of visual disability. Note that 11 of the patients who have negative factor scores also have reasonable visual acuity (6/12) or better.

pairs of canonical variates of correlation are produced, that is, CNVRF1 and CNVFS1, CNVFR2 and CNVRS2, and these pairs are independent of each other. Statistically, only the first pair of canonical correlation coefficients are worth considering. Vision tests with high loading values in column CNVRS1 have a strong positive relationship with high loading disability values in column CNVRF1. Thus, poor performance in a group of tests: near acuity, biocular fields V4e and I4e, CSF(S) at $2 \cdot 88$ cpd, CSF(T) at $0.45 \mathrm{cpd}$ and $10 \mathrm{~Hz}$ indicate that patients would have some difficulty in outdoor navigational activities.
As visual acuity is one of the main criteria for defining partial sight and blindness registration in the United Kingdom we examined the relationship between visual acuity scores and disability (factor) scores derived from the questionnaire. Fig. 2 shows that for a number of patients the degree of disability they experience is not reflected in their visual acuity scores. The 11 patients with visual acuity of $6 / 12$ or better and a negative factor score suffered only mild field loss. It seems that many patients suffer visual disability well before they are eligible for the benefits of registration.

\section{Discussion}

There are two important findings of this study. Firstly, from a battery of vision tests $\operatorname{CSF}(\mathrm{S})$ appears to be the most sensitive method of assessing and quantifying optic nerve damage in glaucoma patients. This is of particular relevance in the early stages of glaucoma when other tests of central vision provide negative results. Secondly, the results from a specific group of vision tests rather than of a single test offers the best predictive relationship between visual defects and visual disability. These tests are $\operatorname{CSF}(\mathrm{S})$ at $2.88 \mathrm{cpd}$ and $\operatorname{CSF}(\mathrm{T})$ at $0.40 \mathrm{cpd}$ and $10 \mathrm{~Hz}$, visual fields V4e and I4e targets, and near visual acuity.

Visual function tests. As expected from the inclusion criteria the glaucoma patients showed monocular and binocular field loss, and these results were significantly different from those of the control subjects. The results also confirm the generally accepted view that visual acuity remains little changed until the later stages of the disease. On the other hand, on the near acuity test patients performed less well than their age matched controls.

The finding of a significant difference between the performance of glaucoma patients and age matched controls on the CSF(S) test confirms the results of other studies. ${ }^{35}$ However, in the present study three discrete response categories were found. Such response categories have not been reported before, perhaps because the population sample in some other studies was too small. On the whole, eyes with advanced field loss produced a type 1 response (loss at all spatial frequencies), whereas eyes with only mild field loss produced only a middle to high spatial frequency loss. This general trend suggests that mechanisms at middle and high spatial frequencies may be more vulnerable in the early stages of the disease. As the disease progresses the lower spatial frequencies become involved. Such a trend would help to explain why losses at low spatial frequencies (below 2 cpd) are not found consistently.

Interestingly, 30 of the eyes had reduced $\operatorname{CSF}(S)$ in the absence of marked field or acuity defects. 
Altogether 37 eyes were classified as having mild field loss, that is, a field of $15^{\circ}$ or more around the fixation point with the $12 \mathrm{e}$ target. Changes in central vision in glaucoma patients are usually thought to occur only in well established or advanced cases. However, these results suggest that the central retina is affected by nerve fibre damage in the early stages of glaucoma. Although it is known that many years may elapse from the onset of the disease to the earliest detectable signs, and that during this time vascular and neural changes are taking place, ${ }^{13}$ until now our conventional methods of measurement have not been sensitive enough to demonstrate early defects. Contrast sensitivity function therefore shows great promise in the monitoring of the progress of the disease and for use as a screening test for nerve damage in ocular hypertension.

Visual defect and visual disability. Although glaucoma patients are often symptomless until late on in the course of the disease we showed by means of the questionnaire a deterioration in the quality of life in patients which manifests itself in an anxiety element, which probably preceeds the stage where real difficulties are experienced. These early difficulties are found particularly in navigation out of doors where such factors as variation in the weather and the amount of traffic can affect the level of confidence of the patient.

Using canonical correlation analysis we could determine which of the visual function tests are the best predictors of the visual disability experienced by the glaucoma patients. A group of tests, visual fields, near acuity, and contrast sensitivity were found to be the best predictors of navigational difficulties. On their own Topcon visual fields may not reflect this disability until the defects are advanced. This is the first time that such an association has been shown between visual defect and perceived visual disability.

The findings of this study raise the question of how residual vision should be assessed for partial sight or blind registration or, indeed, for occupational needs. Clearly, optotype acuity alone is an inadequate method of estimating visual disability, but at present the United Kingdom definitions of blindness include distance visual acuity as the main criterion for registration and fail to supply any formal measure of visual disability. In the present study the use of a questionnaire to measure visual disability has been shown to be a useful tool to supplement the test battery. Contrast sensitivity appears to be a sensitive test for detecting and quantifying visual defect and provides results which correlate positively with perceived disability. Both of these measures would be valuable additions to the conventional methods of vision assessment currently in use.

This research was supported by grant number $81 / 2$ from the Oxford Regional Health Authority.

\section{References}

1 Cullinan TR. The epidemiology of visual disability. Studies of visually disabled people in the community. HSRU Report no. 28. 1977.

2 National Assistance Act 1948, chapter 29, section 64. London: HMSO, 1948.

3 Arden GB, Jacobson JJ. A simple grating test for contrast sensitivity: preliminary results indicate value in screening for glaucoma. Invest Ophthalmol Visual Sci 1978; 17: 23-32.

4 Atkin A, Bodis-Wollner I, Wolkstein M, Moss A, Podos S. Abnormalities of central contrast sensitivity in glaucoma. Am J Ophthalmol 1979; 88: 205-11.

5 Vaegan, Halliday BL. A forced-choice test improves clinical contrast sensitivity testing. BrJ Ophthalmol 1982; 66: 477-91.

6 Hess R, Woo G. Vision through cataracts. Invest Ophthalmol Visual Sci 1978; 17: 428-43.

7 Armaly MF. The visual field defect and ocular pressure level in open angle glaucoma. Invest Ophthalmol Visual Sci 1969; 8: 84-124.

8 Blackwell HR. Studies of psychophysical methods for measuring visual thresholds. J Opt Soc Am 1952; 42: 606-16.

9 Taylor P. A microprocessor controlled gratings generator. $J$ Physiol (Lond) 1978; 284: 20-1P.

10 Cornsweet T. The staircase method in psychophysics. Am J Psychol 1962; 75: 485-91.

11 Wetherill GB. Sequential estimation of quantal response curves. J $R$ Statist Soc series B, 1963; 25: 1-48.

12 Child D. The essentials of factor analysis. London: Holt, Rinehart and Winston, 1979.

13 Quigley HA, Addicks M, Green WR. Optic nerve damage in human glaucoma. Arch Ophthalmol 1982; 100: 135-46. 
away much of the value of several chapters. Ophthalmology par excellence requires colour illustration, and much of the careful text loses its point without colour, for example, in describing 'red' lesions in the retina with a black-and-white fundus photograph. It is also very unsatisfactory for the medical student not to have any simple details of treatment when required. Students have a good knowledge of pharmacology and not even to mention simple antibiotic eye drops in the treatment of conjunctivitis is a remarkable omission. Altogether this is a new book which has not really come off, and it would leave the medical student feeling there were too many loose ends not tied up, especially with regard to simple treatments. JAMES L KENNERLEY BANKES

Visual Disorders in the Handicapped Child. By JoHN L Goble. Pp. 287, SFr. 127.00. Marcel Dekker: New York. 1984.

This excellent book fulfils everything that it sets out to do. The author aims to help general physicians, paediatricians, and neurologists, but also intends to interest ancillary personnel who deal with handicapped children in understanding their visual disorders. Most of the conditions are explained simply, and there are ample further references for those wishing to look further into the subject.

Although the book is laid out in a logical and compartmented way, the author's experience comes through in the practical and clear manner in which he explains many of the conditions and problems that these children have. There is a good author and subject index. If there are any criticisms it may be that there is not enough detail on practical aspects on helping blind babies and children, or on practical aspects of vision testing by non-ophthalmologists. In spite of these criticisms, however, I think that this is a useful book.

DAVID TAYLOR

The Visual System in Myelin Disorders. Eds. A Neetens, A Lowenthal, J J Martin. Pp. 518. Dfl 225.00. Junk: The Hague. 1984.

This book has resulted from a long collaboration in Antwerp between an ophthalmologist (A Neetens), a neurochemist (A Lowenthal), and a neuropathologist (J J Martin). A further eight Belgian contributors were invited in addition to 16 American and 24 European contributors, thus producing a truly international book.

The book is subdivided into sections on basic research into normal and abnormal myelin, and the pathophysiology of myelination. The major section and indeed the major part of the book is devoted to human and animal myelin disorders. This section includes a number of distinguished experts discussing the diagnosis and clinical features of demyelination in the afferent visual system and in the ocular motor system. The metabolic disorders from metachromatic dystrophy to Menkes' disease are fully described. Finally there is a short chapter on treatment.

The chapters vary in length, but on the whole the standard is good. This book therefore provides a comprehensive review on myelin and its disorders, but some com- plex chapters on basic aspects of myelin may frighten many ophthalmologists away. They should, however, avail themselves of the opportunity to browse through this book, for the emergence of nuclear magnetic resonance scans provides an exciting glimpse into the future. They may also obtain stimulating thoughts from other chapters, such as why conjunctival biopsy is used for the diagnosis of neurolipidoses but is not used by ophthalmologists for other diagnostic purposes.

M D SANDERS

\section{Notes}

\section{Adaptive processes}

An international symposium on 'Adaptive processes in visual and oculomotor systems' will be held on 16-20 September 1985 at Asilomar, California, USA. Details from D Zee, Conference cochairman, Department of Neurology, Johns Hopkins Hospital, $600 \mathrm{~N}$ Wolfe Street, Baltimore, MD 21205, USA.

\section{Classification of retinopathy of prematurity}

An international committee with Professor A Garner (UK) in the chair prepared an 'International classification of retinopathy of prematurity.' This classification was published in the $B J O$ last October ( $B r J$ Ophthalmol 1984; 68: 690-7). It has also appeared in Pediatrics 1984; 74: 127-33 (July 1984 issue), Archives of Ophthalmology 1984; 102: 1130-4 (August 1984 issue), and Oftalmolog 1984; 4: 13-6 in an edited version. It has been submitted for publication to several other journals likely to reach an audience concerned with the problems it discusses.

\section{Metabolic eye disease}

The seventh symposium of the International Society on Metabolic Eye Disease will be held at Parma, Italy, on 11-14 May 1986. Theme: 'Neonatal aspects.' For free communications a topic and 500-word abstract should be sent before 1 November 1985 to Heskel M Haddad, MD, Program Chairman, 1125 Park Avenue, New York, NY 10128 , USA.

\section{Correction}

In the article entitled 'Contrast sensitivity and visual disability in chronic simple glaucoma' by J E Ross, A J Bron, and D D Clarke (BrJ Ophthalmol 1984; 68: 821-7) an error occurred in Table 2. The degrees of freedom referred to an analysis of variance, and in each case the figure 1 should have been separated from the subsequent three figures as follows: 1,$184 ; 1,204 ; 1,210 ; 1,141 ; 1,106 ; 1,113 ; 1,101 ; 1,104$. 